\title{
Un piège dans l'analyse des cheveux : les traitements cosmétiques
}

\section{Pitfalls in hair analysis: cosmetic treatment}

\section{Michel YEGLES}

Laboratoire National de la Santé - Toxicologie, Université du Luxembourg - Luxembourg

*Corresponding Author: Michel YEGLES, Laboratoire National de la Santé - Toxicologie, Université du Luxembourg, Campus Limbertsberg, 162a, avenue de la Faïencerie - L-1511 Luxembourg Tél : 3524666446728 - Fax : 352221331 - E-mail : michel.yegles@uni.lu

(Reçu le 7 novembre 2005 ; accepté le 17 décembre 2005)

\section{$R \hat{E} S U M E ́$}

Les traitements cosmétiques des cheveux comme la décoloration et la coloration (utilisation de peroxyde d'hydrogène), les produits pour la permanente et le lissage (utilisation de thioglycollate: d'anmonium suivi de peroxyde d'hydrogène) diminuent la concentration originelle de drogues dans les cheveux. Ces traitements rendent le cheveu poreux et provoquent des changements dans la structure moléculaire du pigment des cheveux ainsi que des dommages aux cuticules. Ceci peut entraîner une perte partielle des substances qui diffusent $\grave{a}$ l'extérieur du cheveu.

Plusieurs études ont montré que le peroxyde d'hydrogène peut aussi changer la structure chimique des drogues comme par exemple pour la cocaïne, les opiacés et les amphétamines. En plus, on a observé une diminution des concentrations de benzodiazépines après une décoloration in vitro de cheveux, qui était plus due à une dégradation chimique par le peroxyde d'hydrogène qu'à un processus de diffusion à l'extérieur du cheveu.

Les traitements de cheveux habituellement utilisés (par exemple les shampooings contenant des détergents anioniques) ont généralement une influence mineure sur la concentration des drogues dans les cheveux. Même l'utilisation de Ultra Clean ${ }^{\mathrm{TM}}$, un shampooing qui dit dissoudre les drogues des cheveux, ne diminue que légèrement les concentrations.

Finalement, nous pouvons conclure qu'il est important de considérer la décoloration des cheveux et la permanente pour l'interprétation des résultats des examens des cheveux, parce qu'après ce genre de traitement, la concentration de substance originale pourrait chuter en dessous de la limite de détection.

\section{SUMMARY}

Hair cosmetic treatments like bleaching and dyeing products (use of hydrogen peroxide), perming or straightening products (use of ammonium thioglycollate followed by hydrogen peroxide) were found to decrease the original drug concentration in hair:

These treatments cause porosity, changes in the molecular structure of the hair pigment, and damages to the cuticle. This may lead to a partial loss of drug substances by leaching of drugs out from the hair matrix.

Several studies have shown that hydrogen peroxide may also change the chemical structure of drugs as for example for cocaine, opiates and amphetamines. Furthermore, a decrease of benzodiazepines concentrations was observed after in vitro bleaching of hair; which was more due to chemically degradation by hydrogen peroxide than to a leaching out process from the hair matrix.

Commonly used hair treatments (e.g. shampoos using anionic detergents) generally have minor influence on hair drug concentration. Even, the use of Ultra Clean ${ }^{\mathrm{TM}}$, a declared drug renover shampoo from hair, only slightly decreased the drugs concentrations in hair:

Finally, we may conclude that is important to consider hair bleaching and perming for the interpretation of hair testing results, because after this hair treatment the original drug concentration may drop below the limit of detection. 


\section{Introduction}

Several factors may affect the concentrations of drugs in hair and thus complicate the interpretation of analytical results. These factors include cosmetic treatment of hair (1).

\section{Cosmetic treatment of hair}

Cosmetics employed to clean, embellish or change the appearance of scalp hair are widely used in our society. This review will be focused on the following cosmetic treatments: shampooing, perming, bleaching and dyeing.

\section{- Shampooing}

Shampoos generally contain anionic detergents like sodium laureth sulphate and sodium lauryl sulphate which are foaming and cleansing components. These surfactants clean hair by stripping soiled sebum from hair shafts.

\section{- Perming}

Perming is done in 2 steps: firstly, there is a reduction step where keratin disulfide bonds are disrupted mainly by alkaline thioglycollate. Secondly, during the reoxidation step a fixing lotion is used restoring $90 \%$ of former disulfide bonds. During this last step acidic solutions of hydrogen peroxide $(2 \%)$ were used.

\section{- Bleaching}

Bleaching corresponds to an oxidative-alkaline treatment in which 6 to $12 \%$ of hydrogen peroxide combined with ammonium or potassium persulfate is used. This leads to a degradation of melanin granule (splitting of disulfide bonds of the melanoprotein) and decolouration of solubilized pigment.

\section{- Dyeing}

Three different types of dyeing exist depending on the duration of the presence of pigments. in hair :

\section{- Temporary dyes}

Dyes form of a coloured film of pigments over each hair which may be easily washed off with shampoo.

\section{- Semi-permanent dyes}

An alkali solution opens the cuticle to allow coloured pigment molecules to get inside the hairs. With each shampooing some pigment molecules were washed away

\section{- Permanent dyes}

Alkali solution opens the cuticle and swells the cortex. Hydrogen peroxide reacts with melanin pigments in the cortex, oxidizing them and breaking them down.

Colourless colorant precursors get inside the hairs and react with hydrogen peroxide to become coloured molecules. At the end, the large pigment molecules are hold in place behind the cuticle which is closed by applying special shampoos or creams. Permanent colouring is not removed by shampooing.

\section{Effect of cosmetic treatment on drug content in hair}

Under normal conditions the intact cuticle is a strong barrier against the loss of drugs.

However, some cosmetic treatments may damage the cuticle, change molecular structure of the hair pigment or degrade incorporated drugs. In generally, this leads to a decrease of drug content in hair.

\section{Shampooing}

Baumgartner et al have shown that daily shampooing does not significantly affect drug content in hair (2). Drug levels could be reduced, but not totally eliminated (3). Thus, after 30 treatments, the hair retained about 20 to $40 \%$ of the original cocaine content (3).

Röhrich et al investigated the influence of a special shampoo Ultra Clean ${ }^{\circledR}$ (Zydot Unlimited, Tulsa, Oklahoma) on the results of hair analyses (4). Referring to the seller, this shampoo should remove all the incorporated drugs from hair. Fourteen hair specimens from persons $(n=14)$ with a known history of drug abuse collected at autopsy were divided into separate strands which were analyzed both after washing with Ultra Clean ${ }^{\circledR}$ and without treatment. The results showed that all drugs originally present in hair were still detected after a single application of Ultra Clean ${ }^{\circledR}$ (table I).

Table I : Effect of Ultra Clean Shampoo on drug content in hair:

\begin{tabular}{|lc|}
\hline Drug & Decrease (\%) \\
\hline THC & 36 \\
amphetamine & 41 \\
MDA/MDMA/MDE & 9 \\
cocaine & 5 \\
codeine & 30 \\
morphine & 26 \\
6-Mam & 9 \\
\hline
\end{tabular}

\section{Perming}

Welch et al treated hair from a drug user that was previously tested positive for cocaine and benzoylecgonine with an alkaline wave solution during $20 \mathrm{~h}$ (3). A drastic decrease of about $95 \%$ for both substances was found. 
Pötsch and Skopp treated in vitro spiked hair and original opiate positive hair with a commercial product (Poly Lock®) (5). Morphine, codeine and dihydrocodeine concentrations decreased after hair treatment; the reduction was more important in original hair than in spiked hair (table II).

Table II : Effect of a perming agent on opiate content in hair.

\begin{tabular}{|lccc|}
\hline & \multicolumn{3}{c|}{ Decrease (\%) } \\
\hline & morphine & codeine & dihydrocodeine \\
Spiked hair & 79 & 79 & 70 \\
Original opiate positive hair & 100 & 94 & 100 \\
\hline
\end{tabular}

Takayama et al treated in vitro methamphetamine positive hair with $5 \%$ ammonium thioglycollate with about $1 \%$ of ammonia $(3,6)$. They found a decrease of about $100 \%$ of methamphetamine (MA) and amphetamine (AM) after treatment.

\section{Dyeing}

Welch et al did a colour rinse on hair specimens of a known cocaine user during $20 \mathrm{~h}$ and noted a decrease of both cocaine (about $18 \%$ ) and benzoylecgonine (about $5 \%)(3,6)$.

Jurado et al compared dyed hair segments with untreated hair segments from drug users (7). In dyed hair segments a decrease of concentrations for cocaine and benzoylecgonine concentrations was reported lower (43.4 and $36.6 \%$ respectively), as well as for codeine, 6-MAM and morphine concentrations (29.5, 41.3 and $61.2 \%$ respectively).

Furthermore, a decrease of $34 \%$ was noted for THC in dyed hair portions.

\section{Bleaching}

The effect of bleaching on drug concentration in hair for cocaine and opiates is resumed in table III and IV respectively.

Table III : Effect of bleaching on cocaine concentration in hair.

\begin{tabular}{|cccc|}
\hline & Decrease $(\%)$ & & References \\
\hline cocaine & benzoylecgonine & cocathylene & \\
\hline 90 & 80 & - & $(3)$ \\
62.2 & 42.9 & 58.8 & $(8)$ \\
66.2 & 61.2 & - & $(7)$ \\
24.6 & 67.7 & 61.8 & $(9)$ \\
\hline
\end{tabular}

Cocaine and metabolites as well as codeine, morphine and 6-MAM concentrations decreased after hair bleaching.
Table IV : Effect of bleaching on opiates concentration in hair:

\begin{tabular}{|cccc|}
\hline & Decrease (\%) & & References \\
\hline Codeine & 6-MAM & morphine & \\
\hline 75 & 86 & 89 & $(8)$ \\
94 & - & 94 & $(5)$ \\
68.8 & 65.9 & 80.6 & $(7)$ \\
57 & 89 & 67 & $(9)$ \\
\hline
\end{tabular}

Moreover, for THC Jurado et al reported a diminishment of $12.3 \%$ in bleached hair segments compared to untreated hair segments (7).

After in vitro bleaching of benzodiazepines positive hair with a commercial cosmetic preparation (Poly Blonde, Intensive Blond from Schwarzkopf), concentrations for diazepam, nordazepam and 7-aminoflunitrazepam decreased (diminution of 39.7, 67.7 and $61.8 \%$ respectively) (9).

Ethyl glucuronide (EtG), a marker of excessive alcohol consumption in hair was shown to diminish after bleaching. Thus, after in vitro treatment of EtG positive by a commercial cosmetic preparation (Poly Blonde, Intensive Blond, Schwarzkopf) (10), a decrease of $78 \%$ of EtG content in hair was reported. For the other alcohol marker in hair, the fatty acid ethyl-esters (FAEE), bleaching as well as shampooing, perming and dyeing only slightly decrease their content in hair. Thus, no false negative results were generated after cosmetic treatment. However, the use of hair lotions containing higher concentrations of ethanol may cause a false positive result (11).

\section{Mechanisms involved in the decrease of drug content in hair by cosmetic treatment}

Takayama et al incubated methamphetamine and amphetamine in a perming solution containing $5 \%$ ammonium thioglycollate with about $1 \%$ of ammonia (6). As methamphetamine and amphetamine were shown to be stable, the authors concluded that the decrease of AM and MA after perming is more due to leaching out of the hair matrix than to chemical degradation.

Pötsch and Skopp proposed the following processes involved in the decrease of drug content by dyeing or bleaching. Firstly, the decrease may be due to a leaching out of the hair matrix due to solubilisation by hydrogen peroxide of melanin granules known to be 
binding sites of drugs in hair. Secondly, the diminution may be due to chemical degradation by hydrogen peroxide (5). To confirm this last hypothesis, Yegles et al incubated different drugs during $20 \mathrm{~min}$ in a hydrogen peroxide solution $(30 \%)$. The results were reported in table V. A decrease was observed for all the drugs analysed from $23.6 \%$ for diazepam to 94.8 for 7 -aminoflunitrazepam. Thus, the results suggest that the drugs were chemically unstable in presence of hydrogen peroxide (9).

Table $\mathrm{V}:$ Effect of $\mathrm{H}_{2} \mathrm{O}_{2}$ on drug stability.

\begin{tabular}{|lc|}
\hline Drug & Decrease (\%) \\
\hline diazepam & 23.6 \\
nordazepam & 31.6 \\
7-aminoflunitrazepam & 94.8 \\
benzoylecgonine & 60.4 \\
cocaine & 34.2 \\
cocaethylene & 38.4 \\
codeine & 63.6 \\
morphine & 84.1 \\
6-Mam & 88.0 \\
\hline
\end{tabular}

In another study Tanaka et al incubated methamphetamine, cocaine, morphine and codeine in hydrogen peroxide (30\%) during $24 \mathrm{~h}$ at $39^{\circ} \mathrm{C}(12-14)$. All the drugs were unstable in presence of hydrogen peroxide. Furthermore, the authors identified reaction products, mainly oxide or hydroxyl products. For methamphetamine, $\mathrm{N}$-oxide and $\mathrm{N}$-hydroxyl methamphetamine, for cocaine, EME and benzoylecgonine as well as hydroxycocaine and dihydroxycocaine, for morphine hydroxymorphine and for codeine hydroxycodeine.

\section{Conclusions}

Daily shampooing only slightly effects drug content in hair, mainly because the cuticle remains intact. Perming yielded a dramatic decrease of drug content, mainly by a leaching out process from the hair matrix. Dyeing and bleaching produced a relatively important diminution of drug content by a leaching out process by destroying hair binding sites and by chemical degradation of incorporated drugs by $\mathrm{H}_{2} \mathrm{O}_{2}$.

Finally, the different studies on cosmetic treatment in hair show that it is important to consider cosmetic treatment mainly dyeing, bleaching and perming. These hair treatments may drop the original drug concentration below the limit of detection of the analytical methods generating false negative results.

\section{References}

1. R. Wennig. Potential problems with the interpretation of hair analysis results. Forensic Sci. Int.107: 5-12 (2000).

2. W. Baumgartner, V. Hill, and W. Bladh. Hair analyis for drugs of abuse. J. Forensic Sci.34: 1433 (1989).

3. M.J. Welch, L.T. Sniegoski, C.C. Allgood, and M. Habram. Hair analysis for drugs of abuse: evaluation of analytical methods, environmental issues, and development of reference materials. J. Anal. Toxicol.;17: 389-398. (1993).

4. J. Rohrich, S. Zorntlein, L. Potsch, G. Skopp, and J. Becker. Effect of the shampoo Ultra Clean on drug concentrations in human hair. Int. J. Legal Med.113: 102$106(2000)$.

5. L. Potsch, and G. Skopp. Stability of opiates in hair fibers after exposure to cosmetic treatment. Forensic Sci. Int.81: 95-102 (1996).

6. N. Takayama, S. Tanaka, R. Kizu, and K. Hayakawa. High-performance liquid chromatography study on effects of permanent wave, dye and decolorant treatments on methamphetamine and amphetamine in hair. Biomed. Chromatogr.13: 257-261 (1999).

7. C. Jurado, P. Kintz, M. Menendez, and M. Repetto. Influence of the cosmetic treatment of hair on drug testing. Int. J. Legal Med.110: 159-163 (1997).

8. V. Cirimele, P. Kintz, and P. Mangin. Drug concentrations in human hair after bleaching. J. Anal. Toxicol.19: 331332 (1995).

9. M. Yegles, Y. Marson, and R. Wennig. Influence of bleaching on stability of benzodiazepines in hair. Forensic Sci. Int. 107: 87-92 (2000).

10. M. Yegles, A. Labarthe, V. Auwarter, S. Hartwig, H. Vater, R. Wennig, and F. Pragst. Comparison of ethyl glucuronide and fatty acid ethyl ester concentrations in hair of alcoholics, social drinkers and teetotallers. Forensic Sci. Int. 145: 167-173 (2004).

11. S. Hartwig, V. Auwarter, and F. Pragst. Effect of hair care and hair cosmetics on the concentrations of fatty acid ethyl esters in hair as markers of chronically elevated alcohol consumption. Forensic Sci. Int.131: 90-97 (2003).

12. S. Tanaka, R. Iio, S. Chinaka, N. Takayama, and K. Hayakawa. Identification of reaction products of methamphetamine and hydrogen peroxide in hair dye and decolorant treatments by high-performance liquid chromatography/mass spectrometry. Biomed. Chromatogr.15: 45-49 (2001).

13. S. Tanaka, R. lio, S. Chinaka, N. Takayama, and K. Hayakawa. Analysis of reaction products of cocaine and hydrogen peroxide by high-performance liquid chromatography/mass spectrometry. Biomed. Chromatogr.16: 390394 (2002).

14. S. Tanaka, R. Iio, S. Chinaka, N. Takayama, and K. Hayakawa. Analysis of reaction products of morphine and codeine with hydrogen peroxide by high-performance liquid chromatography/mass spectrometry. Anal. Sci.19: 163-165 (2003). 